not a therapeutic theory. There seems to be no doubt but that this frequent administration of antiseptics has an inhibitory influence on the typhoid bacilli, checking their activity, hence preventing the development of toxins, the absorption of which no doubt causes the grave nervousness in so many cases. I will say, in conclusion, that in none of these cases did fever exist over twenty-one days after beginning.

Yours faithfully,

Wm. Bayard Shields, M.D.

\section{Treatment of Typhoid Fever.}

Oran, Mo., Jan. 8, 1895.

To the Editor:-In our Journal of January 5, I find a report on typhoid fever by Dr. Woodbridge and it reminds me of a report I made to the Southeastern Missouri Medical Association a few days before the Doctor made his report at Hot Springs. I reported a case of typhoid fever treated with hyposulphite soda and Fouler's solution, which gained over a pound a day during treatment. He ate his meals regularly, went to the table and to the privy (fifty yards distant from bis hotel) his temperature ranging from $1021 / 2$ to 105 for fifteen days. He ate largely of green apples, dates, oranges, lemons, anything he wanted (and could get), never complained of any pain, said he felt firstrate all the time, slept well, read the newspapers by day, and was a great Breckinridge man, they both being Kentuckians. I am as positive that this man had a genuine case of typhoid fever as I am that I am writing this squib.

Now what does my report and that of Dr. Woodbridge teach? Nothing, only that typhoid fever does not kill everybody that has it. I treated a babe, 2 years old, last week with as typical a case of typhoid fever as those described by Dr. Love in this same number of the JournaL. I gave it calomel and Dovers' powder $1 . \mathrm{gr}$. each, every four hours for six days and Fowler's solution (Squibb's) $1 / 3$ of a drop every two hours during the same time. This case was clear of fever on the tenth day and called for food. Can Dr. Woodbridge or any other man, do any better for typhoid fever than I did in these two cases? We did not use the same treatment but obtained the same results. Therefore the treatment is not entitled to all the credit. ${ }^{1}$ I gave my doses two hours apart, allowing some time for sleep between doses. Any doctor who gives medicine every fifteen minutes for twenty-four hours ought to have mild cases to treat or be dosed himself for the next twenty-four hours.

Dr. Woodbridge is an enthusiast, and evidently a good man, but there is nothing in his treatment that is new or an improvement on mine. Mine will only cure cases that would probably have gotten well without it-typho:d fever comes as near having its own way as any disease we have to treat. Dr. Woodbridge's treatment is like the homeopaths or the old woman's butter, "If it does no good it will do no harm." Dr. Woodbridge is full of enthusiasm; I am full of gall. This makes a stand off. He tells what he thirks is true; I tell what I think is true. Another stand off. The reader can take his choice of treatments-not forgetting that typhoid fever kills under all kinds of treatment, and that many cases get well under the most unfavorable conditions. W. P. Howle, M.D.

\section{A New Truss-'The Nagler Shield.}

San Francrsco, Cal., Dec. 29, 1894.

To the Editor:-For the past few months I have been carefully investigating the virtues of a new mechanical device to act as a truss and abdominal supporter wherever such is indicated. It absolutely controls all protrusion and reduces

1 This is a non-sequitur, for Fowler's Solution is an excellent germicide, so also is calomel, and sodium hyposulphite.-ED. to a minimum all discomfort from pressure or friction. It consists in its main features of an aluminium shield, carefully molded to the abdominal periphery, and suitably modified to conform to the anatomic requirements of either sex. The shield is lined with soft felt, in which pockets are formed, which can be filled with additional packing, should any particular case demand such support.

In extreme cases a padded metallic ring, surrounding the penis is fastened underneath on top of arched cut away portion of the shield, and this ring is pressed against that part of the pad where the opening for the scrotum is set in and when so adjusted to the body completely controls all possible prolapsus.

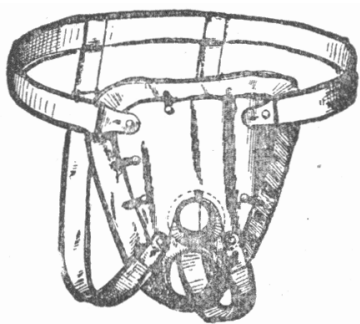

The Nagler shield.

The pressure for the truss is created by the fastening of an elastic belt around the body, which is attached to a series of pins placed around the borders of the shield; this can be graded to suit the amount of pressure required. An additional mechanism prevents all vertical movement.

The complete truss is so simple and yet so effectual that notbing but actual experience of its use will convince those unacquainted with its virtues. The lightness of the material - an infantile umbilical truss not weighing over one ounce -and the freedom from friction go far to commend the application of this truss in all reducible hernias or lax abdominal walls.

Fred WV. D'Evetys, M.D.

\section{One Hundred Thousand More.}

Parkersburg, W. Va., Jan. 9, 1895.

To the Editor:-In your article on "Smallpox in 1894," in Journal of January 5, occurs a clerical error on page 27 , which destroys the force of the argument. Should read 112,300 deaths instead of 12,300 , making the value of vaccination much less than it is. Yours, W. H. ShARP, M.D.

\section{Doctor Dana o. Weeks.} Marion, OHIo, Jan. 12, 1895.

To the Editor:-A mistake occurs in this week's issue of the Journal, page 62, under Society News. Dana O. Weeks was elected President of Marion County Medical Societynot Dana $O$. Webb. Very truly yours, O. W. WEEKS, M.D.

\section{PUBLIC HEALTH.}

Board of Health of North Carolina.-The December Bulletin of the North Carolina Board of Health makes announcement of the resignation of the President, Dr. H. T. Bahnson, of Salem, to become a director of the State Hospital at Morganton. Dr. George G. Thomas, of Wilmington, has been elected to succeed to the presidency. Dr. William P. Beall, of Greensborough, has been appointed by the Governor to fill the place in the Board.

Windmills for Sanitation.-A paper, at the Mexican capital, reports that a new project is on foot for the better sanitation of the sewer system of the City of Mexico. It is purposed to construct twenty-five windmills, at a cost of $\$ 25$, 